\title{
Removal of nitrate, ammonia and phosphate from aqueous solutions in packed bed filter using biochar augmented sand media
}

\author{
Ali El Hanandeh ${ }^{1, *}$, Aswin Bhuvaneswaran ${ }^{1}$, Philiphi de Rozari ${ }^{1,2}$ \\ ${ }^{1}$ School of Engineering, Griffith University, Nathan, QLD Australia \\ ${ }^{2}$ Nusa Cendana University, Kupang, Indonesia
}

\begin{abstract}
Nutrients from wastewater are a major source of pollution because they can cause significant impact on the ecosystem. Accordingly, it is important that the nutrient concentrations are kept to admissible levels to the receiving environment. Often regulatory limits are set on the maximum allowable concentrations in the effluent. Therefore, wastewater must be treated to meet safe levels of discharge. In this study, laboratory investigation of the efficiency of packed bed filters to remove nitrate, ammonium and phosphate from aqueous solutions were conducted. Sand and sand augmented with hydrochloric acid treated biochar (SBC) were used as packing media. Synthetic wastewater solution was prepared with $\mathrm{PO}_{4}{ }^{3-}$, $\mathrm{NO}_{3}{ }^{-}, \mathrm{NH}_{4}{ }^{+}$concentrations $20,10,50 \mathrm{mg} / \mathrm{L}$, respectively. Each experiment ran for a period of five days; samples from the effluent were collected on alternate days. All experiments were duplicated. Over the experiment period, the average removal efficiency of $\mathrm{PO}_{4}{ }^{3-}, \mathrm{NO}_{3}{ }^{-}, \mathrm{NH}_{4}{ }^{+}$were $99.2 \%$, $72.9 \%, 96.7 \%$ in the sand packed columns and $99.2 \%, 82.3 \%, 97.4 \%$ in the SBC packed columns, respectively. Although, the presence of biochar in the packing media had little effect on phosphate and ammonium removal, it significantly improved nitrate removal.
\end{abstract}

\section{Introduction}

Nutrient removal from wastewater before discharge to natural water bodies is essential because excessive nutrient loads can lead to eutrophication. Traditional wastewater treatment methods such as activated sludge are not efficient in removing nutrients. Therefore, it is important to find cost effective technologies to reduce the nutrient concentrations to admissible levels to the receiving water bodies. Filtration is a well-established technology for wastewater treatment. The removal efficiency of nutrients in filters depends on the filtration media used. The use of activated carbon (AC) can enhance the performance of filter media

\footnotetext{
${ }^{*}$ Corresponding author: a.elhanandeh@griffityh.edu.au
} 
because of its high surface area and adsorption capacity. Nevertheless, AC is very expensive which makes it impractical for treatment of large volumes of wastewater [1].

In recent years, the interest in using biochar in wastewater treatment has been increasing due to its low cost of production, relatively high surface area and active surface functional groups $[2,3]$. A number of researchers reported that biochar can be used to remove nutrients from aqueous solutions in batch and column experiments [4-6]. Furthermore, Gupta et al. [7] reported that augmenting media with biochar in constructed laboratory scale constructed wetland improved nitrogen and phosphorus removal from wastewater. On the other hand, Yao et al. [6] found that the effects of the addition of biochar to sand media were not universal and it depended on the biomass origin of the biochar. Other researchers also reported that biochar preparation conditions, such as pyrolysis method, pre-treatment, heating rate and time and final pyrolysis temperature also affected the adsorption characteristics of the biochar $[8,9]$. Therefore, the aim of this study was to investigate the suitability of commercially produced biochar derived from eucalyptus woody biomass prepared under slow pyrolysis conditions at pyrolysis temperature of $500{ }^{\circ} \mathrm{C}$ as a media amendment in sand filters for the removal of phosphate, nitrate and ammonium from aqueous solutions.

\section{Material and methods}

The effect of the addition of biochar to sand media on nutrient removal from aqueous solutions was investigated using laboratory scale column experiments. All experiments were duplicated. In total four (4) plexi-glass columns with internal diameter of $56 \mathrm{~mm}$ and 200 $\mathrm{mm}$ height were used (Figure 1).

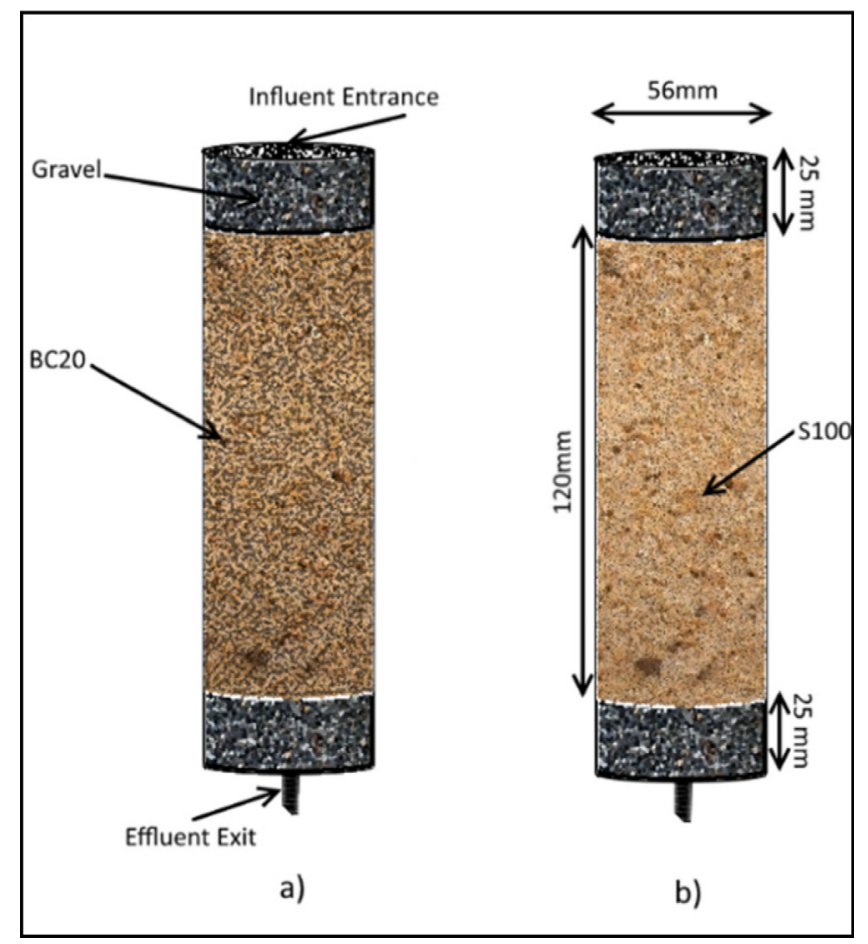

Fig. 1. Filter design (a) sand and (b) SBC media. 


\subsection{Material procurement characterisation and preparation}

Sand was purchased from a local hardware store. Biochar was purchased from a local biochar supplier. The biochar was prepared from eucalyptus woody biomass using slow pyrolysis method at $500{ }^{\circ} \mathrm{C}$.

Two treatments were prepared: sand alone (control) and sand mixed with $20 \%$ biochar by volume, henceforth referred to as SBC. Both media types were washed with distilled deionised water and $0.1 \mathrm{M} \mathrm{HCl}$ acid to remove impurities. Then the media was rinsed with deionised distilled water until the $\mathrm{pH}$ of the effluent was neutral. The basic characteristics of both media are given in Table 1 .

Table 1. Physical characteristics of media.

\begin{tabular}{|c|c|c|}
\hline Property & Sand & SBC \\
\hline Bulk density $\left(\mathrm{g} / \mathrm{cm}^{3}\right)$ & $\bullet 1.46$ & $\bullet 1.22$ \\
$\bullet \quad$ Dry & $\bullet 1.80$ & $\bullet 1.58$ \\
\hline Wet & 29.8 & 39.2 \\
\hline Porosity $(\%)$ & $125<\mathrm{d}<710$ & $125<\mathrm{d}<710$ \\
\hline Particle Grain Size $(\mu \mathrm{m})$ & & \\
\hline
\end{tabular}

\subsection{Column packing}

First gravel layer was added to a depth of $25 \mathrm{~mm}$. This layer acts as drainage layer. The sand or SBC were added in three layers to total height of $120 \mathrm{~mm}$. After adding each layer, the layer was compacted by dropping a $50 \mathrm{~g}$ weight 10 times from $100 \mathrm{~mm}$ height. Finally another layer of gravel $(25 \mathrm{~mm})$ was add onto to ensure equal distribution of water, prevent scouring of the filter media and prevent floatation of biochar. To prevent media mixing, plastic fabric (mesh) were laid between grave and sand media. All media were wet packed in the columns. Figure 1 shows a schematic diagram of the packed columns.

\subsection{Chemicals}

All chemical were laboratory grade chemicals. Solution containing phosphate, nitrate and ammonium with concentrations of 20,10 and $50 \mathrm{mg} / \mathrm{L}$, respectively was prepared by adding $176.5 \mathrm{mg}$ of $\mathrm{KH}_{2} \mathrm{PO}_{4}, 145.35 \mathrm{mg}$ of $\mathrm{KNO}_{3}$ and $148.58 \mathrm{mg}$ of $\mathrm{NH}_{4} \mathrm{Cl}$ to a $2 \mathrm{~L}$ measuring flask and then filling it to the $2 \mathrm{~L}$ mark with deionized water. The $\mathrm{pH}$ of the solution was 5.53. The stock was stored in the fridge at $4{ }^{\circ} \mathrm{C}$.

\subsection{Loading of the columns, sample collection and analysis}

Fifty millilitres $(50 \mathrm{~mL})$ of the stock solution was added daily to each column. The effluent was collected in a beaker, the effluent was discarded at the end of each day. Samples were collected on alternate days (1, 3 and 5) from the beaker. Samples were frozen until analysed.

Phosphate in the effluent were analysed using Spectrophotometry and the Molybdenum Blue Method. Nitrate and ammonium were analysed using Discrete Chemistry Analyser (Westco Smartchem 200). MS Excel ${ }^{\mathrm{TM}}$ with data analysis Toolpack was used to perform all statistical tests and data analysis.

\section{Results and discussion}

The concentration of different nitrogen compounds in the effluent as well as the removal efficiency of the corresponding compounds are shown in figures 2-4. The $\mathrm{NO}_{3}{ }^{-}$ 
concentration were in the range 2.3-3.4 mg/L-N in the effluent from the sand media and 1.5$2.2 \mathrm{mg} / \mathrm{L}-\mathrm{N}$ in the SBC effluent. The $\mathrm{NH}_{4}^{+}$concentration ranged from 0.2 to $4.1 \mathrm{mg} / \mathrm{L}-\mathrm{N}$ in the effluent from sand and SBC media. In the case of phosphate, the concentration in the effluent from the sand media ranged from 0.12 to $0.24 \mathrm{mg} / \mathrm{L}-\mathrm{P}$ and 0.08 to $0.16 \mathrm{mg} / \mathrm{L}-\mathrm{P}$ in the effluent from the SBC media.

\subsection{Nitrate removal}

Figure 2 shows the concentration of the nitrate ion in the effluent from the sand and SBC media as well as the removal efficiency of nitrate by each media. As expected, Figure 2 shows that the concentration of NO3 - in the effluent increased over time as active adsorption sites were being occupied. Nevertheless, the NO3- concentration was reduced significantly from $20 \mathrm{mg} / \mathrm{L}-\mathrm{N}$ in the influent to a 5 -day average of $2.77 \pm 0.43$ and $1.81 \pm 0.23 \mathrm{mg} / \mathrm{L}-\mathrm{N}$ in the effluent from the sand and SBC media, respectively. This reduction represents an average removal efficiency of $72.3 \pm 4.7 \%$ and $81.9 \pm 2.5 \%$ in the sand and SBC media, respectively. Figure 2 also shows that the $\mathrm{NO}_{3}{ }^{-}$concentration in the effluent from the $\mathrm{SBC}$ media was consistently lower that in the sand media which indicates that the addition of biochar had positive effect on the capacity of the media to remove nitrate. On average, the SBC media retained $13.3 \%$ more nitrate than sand alone. A t-test confirmed that improved removal rate was significant at $\alpha=0.05$ ( $p=0.0007)$. Yao, et al. [6] tested 13 biochars and reported that the majority of them had little or no ability to remove nitrate. Nevertheless, they further reported that sandy soil augmented with $2 \%$ biochar derived from peanut hull or Brazilian pepperwood released approximately 34\% less nitrate than soil alone. Our results suggest that biochar derived from eucalyptus is one of the few biochars that has the capacity to improve nitrate removal. This is important in Australian context as well as other countries were eucalyptus is abundant.

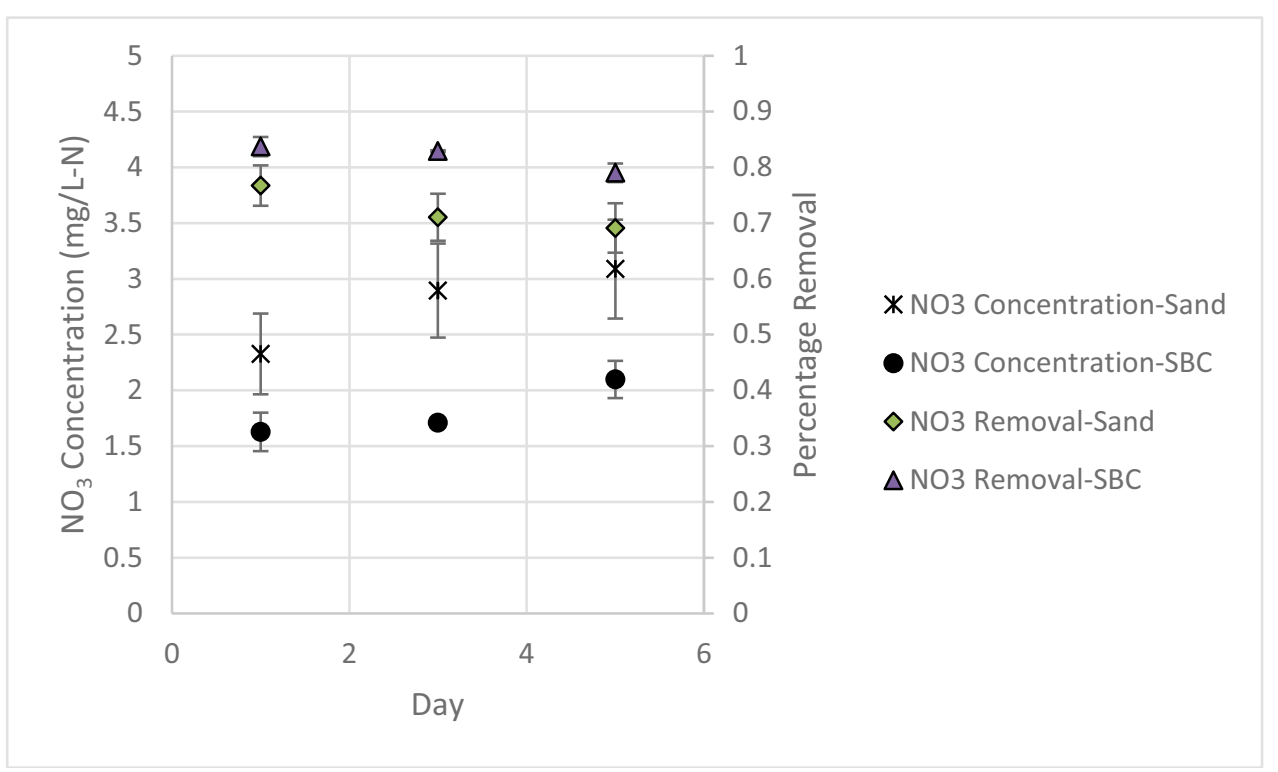

Fig. 2. Nitrate concentration in the effluent and removal efficiency. 


\subsection{Ammonium removal}

The concentration of ammonium in the effluent as well as the removal efficiency of ammonium in each media are shown Figure 3. The results show that the ammonium concentration in the effluent from both media were similar. Suggesting that the addition of biochar did not have adverse effect on the media. In the earlier mentioned study, Yao, et al. [6] reported that nine out of the 13 biochars had some capacity to remove ammonium with varying efficiencies. Hale, et al. [10] who studied the adsorption of ammonium by biochars prepared from corn cob and cacao shell suggested that ammonium is weakly adsorbed on the surface of the biochar through electrostatic exchanges with other cationic species. This is consistent with the findings of Taghizadeh-Toosi, et al. [11] who reported that ammonium adsorbed by biochar was readily available to plants.

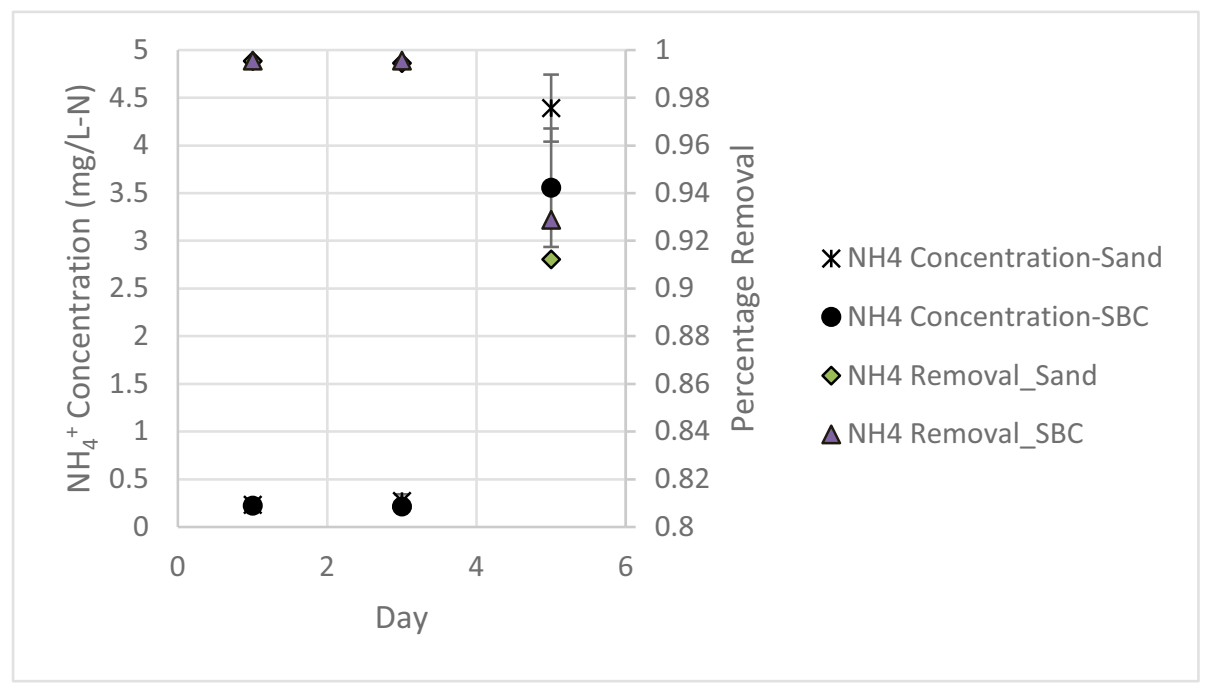

Fig. 3. Ammonium concentration in the effluent and removal efficiency.

Upon close inspection of the results, a trend was observed which indicated that the addition of biochar may enhance the $\mathrm{NH}_{4}{ }^{+}$removal efficiency overtime. Unfortunately, the experiment was terminated after 5 days, thus being unable to establish the long term effect. Therefore, we suggest that the effect of biochar addition should be studied over a longer period of time.

\subsection{Phosphate removal}

Figure 4 shows the phosphate concentration in the effluent from sand and SBC filter media. The removal rate is also shown in Figure 4. Effluent from sand consistently had higher phosphate concentration than that from the SBC media, thus suggesting that the addition of biochar had positive effect on phosphate removal. The removal efficiency of phosphate has remained constant over the period of the experiment. This is unlike the case for nitrate and ammonium which showed a decreasing trend overtime. 


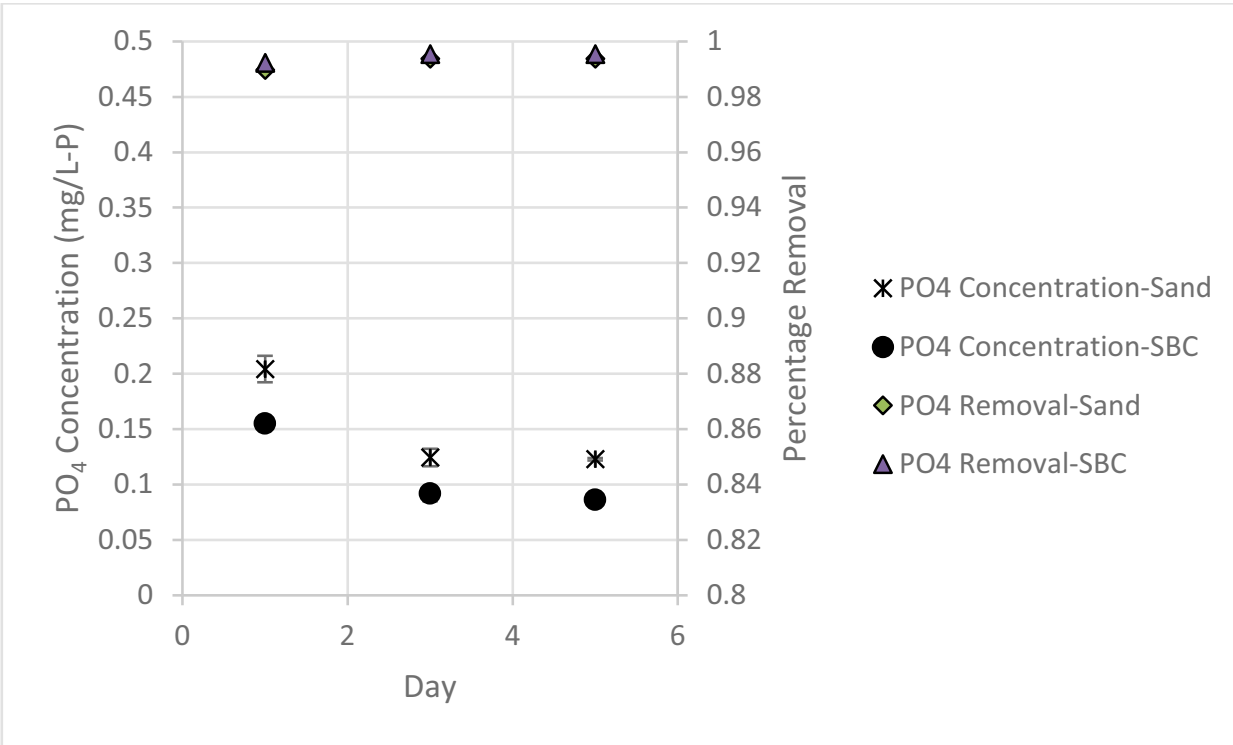

Fig. 4. Phosphate concentration in the effluent and removal efficiency.

The removal efficiency of phosphate in sand was extremely high $(>99 \%)$; as a result, the effect of biochar addition on the removal efficiency (in relative terms) was insignificant. A number of researchers reported that biochar had little capacity for $\mathrm{PO}_{4}{ }^{3-}$ removal $[6,12]$. On the other hand, others reported that biochar has the capacity to remove or enhance phosphorus removal $[4,5,7,13]$. The apparently conflicting findings can be explained by the fact that the characteristics of biochar depend on the parent biomass and preparation conditions which affect their adsorption capacity of different chemicals $[9,14]$.

\section{Conclusion}

Biochar prepared from eucalyptus woody biomass was used as augmenting material for sand filters in laboratory scale column experiments. The effect of biochar addition on nutrients removal $\left(\mathrm{NH}_{4}{ }^{+}, \mathrm{NO}_{3}{ }^{-}, \mathrm{PO}_{4}{ }^{3-}\right)$ were investigated. The results showed that sand media was very effective in removing nutrients from aqueous solutions. The results further revealed that the addition of biochar had enhanced the removal efficiency of nutrients. The addition of biochar had the greatest effect on the removal of nitrate which increased by $13.3 \%$. In the cases of phosphate and ammonium the improvement was marginal. Nevertheless, a developing trend of enhanced performance over time was detected. It is recommended that the long term effect of biochar addition be further investigated.

\section{References}

1. D. Mohan, A. Sarswat, Y. S. Ok, and C. U. Pittman Jr, Bioresource Technol. 160, 191 (2014).

2. M. Ahmad, A. U. Rajapaksha, J. E. Lim, M. Zhang, N. Bolan, D. Mohan, et al., Chemosphere 99, 19 (2014).

3. H. N. Tran, S.-J. You, and H.-P. Chao, Waste manage. Res. 34, 129 (2016).

4. T. A. Ghezzehei, D. V. Sarkhot, and A. A. Berhe, Solid Earth 5, 953 (2014).

5. Y. Yao, B. Gao, M. Inyang, A. R. Zimmerman, X. Cao, P. Pullammanappallil, et al., J. Hazard. Mater. 190, 501 (2011). 
6. Y. Yao, B. Gao, M. Zhang, M. Inyang, and A. R. Zimmerman, Chemosphere, 89, 1467 (2012).

7. P. Gupta, T.-w. Ann, and S.-M. Lee, Environ. Eng. Res. 21, 36 (2016).

8. C. A. Takaya, L. A. Fletcher, S. Singh, K. U. Anyikude, and A. B. Ross, Chemosphere 145, 518 (2016).

9. Z. Mahdi, A. El Hanandeh, and Q. Yu, Waste Biomass Valor. (2016).

10. S. E. Hale, V. Alling, V. Martinsen, J. Mulder, G. D. Breedveld, and G. Cornelissen, Chemosphere 91, 1612 (2013).

11. A. Taghizadeh-Toosi, T. J. Clough, R. R. Sherlock, and L. M. Condron, Plant and Soil 350, 57 (2012).

12. P. de Rozari, M. Greenway, and A. El Hanandeh, Sci. Total Environ. 569-570, 123 (2016).

13. J. D. Streubel, H. P. Collins, J. M. Tarara, and R. L. Cochran, J. of Environ. Qual. 41, (2012).

14. S. Yavari, A. Malakahmad, and N. B. Sapari, Environ. Sci. Pollut. R., 1 (2016). 